\title{
Obsolescência programada em serviços de saúde: o caso da Máfia das Próteses
}

\section{Planned obsolescence in public health services: the Prosthetic Mafia case}

\section{Rafael de Almeida Martarello ${ }^{a}$}

(D) https://orcid.org/0000-0002-2092-3190

E-mail: martarellorafaeløgmail.com

aniversidade Estadual de Campinas. Instituto de Economia. Campinas, SP, Brasil.

\section{Correspondência}

Rafael de Almeida Martarello

Rua Pitágoras, 353, Cidade Universitária, Campinas, SP, Brasil.

CEP $13083-857$.

\section{Resumo}

Obsolescência programada é um conjunto de ações empreendidas por parte do produtor com o objetivo de estabelecer o decaimento gradativo de algum atributo de uma mercadoria para, assim, estimular artificialmente a demanda pelo consumo. A literatura sobre o fenômeno tem apontado como vítimas somente indivíduos e, como forma de manifestação do fenômeno, objetos. Este trabalho aponta a ocorrência do fenômeno de obsolescência programada em serviços públicos de saúde. Para isso, é empreendido um estudo exploratório-interpretativo de abordagem qualitativa e utilizado como estratégia de pesquisa o estudo de caso. A unidade de análise foi a nomeada Máfia das Próteses e, para coleta de dados, foram empregadas as técnicas de pesquisa bibliográfica e documental. Como resultado, foram selecionados e expostos três casos da ocorrência do fenômeno em cirurgias. Foi também realizado um esforço interpretativo dos condicionantes, da dinâmica e dos efeitos da prática de sabote cirúrgico com objetivo de estimular a demanda por serviços médicos e equipamentos médico-hospitalares. Como contribuição, este estudo realiza o delineamento dos elementos que caracterizam a ocorrência deste fenômeno em serviços médicos. Além disso, inaugura uma agenda de futuros estudos que abordam tanto o Estado sendo vitimado pela prática, quanto a ocorrência do fenômeno no setor de serviços.

Palavras-chave: Obsolescência Planejada; Estudos Sociais da Ciência e Tecnologia; Gestão Hospitalar; Órteses, Próteses e Materiais Especiais. 
Planned obsolescence is a set of actions undertaken by the producer to establish the gradual decay of some attribute of a commodity, artificially stimulating the demand for consumption. The literature on the phenomenon has identified only individuals as victims and objects as forms of expression. This study reports the occurrence of planned obsolescence in public health services. To this end, it consists of an exploratoryinterpretative study with a qualitative approach, using the case study of the so-called Prosthetic Mafia. Data were collected by means of bibliographic and documentary research, resulting in three cases that expose the phenomenon occurrence in surgeries. The results were analyzed through an attempt to interpret the conditions, dynamics, and effects of the practice of surgical sabotage to stimulate the demand for medical services and medical-hospital equipment. This study outlines the elements that characterize planned obsolescence occurrence in medical services, inaugurating an agenda of future studies that address both the State being victimized by the practice and the phenomenon in the service sector. Keywords: Programmed Obsolescence; Social Studies in Science and Technology; Hospital Management; Orthotics, Prosthetics and Special Materials.
No Brasil, há 302.610 óbitos relacionados a condições adquiridas nos hospitais (Couto et al., 2017), ou seja, esta seria a segunda maior causa de morte no país. Falhas gerenciais e/ou operacionais na saúde acarretam gastos milionários, sem contar os custos sociais. Em uma única ação do Tribunal de Contas do Distrito Federal, foi constatado que a ineficiência na gestão de órteses, próteses e materiais médicos especiais (OPMEs) causou, em dois anos, um prejuízo de R\$ 75 milhões aos cofres públicos (Distrito Federal, 2015). Para piorar o cenário, a área da saúde tem sido usada para prosperidade fraudulenta de agentes particulares.

A Máfia das Próteses é um sofisticado esquema criminoso organizado para fraudar procedimentos cirúrgicos, com o objetivo de induzir a demanda por serviços e dispositivos médicos. Estas ações ocorreram tanto no sistema público de assistência médica, quanto no privado, concentrando-se, principalmente, em áreas que contam com o uso de OPMEs.

Embora haja, para um dos desembargadores (vítima das ações da Máfia das Próteses), uma "organização criminosa nacional, embora pulverizada em diversos núcleos, em diversas quadrilhas" (Brasil, 2015a, §656), a crença que move este estudo é a de que há uma lei que governa estas ações: a obsolescência programada.

A obsolescência programada deve ser entendida como uma téchne que orienta a produção de objetos e serviços para uma deformidade que destina a mercadoria ao fim da sua vida útil. Este fenômeno tem sido o principal indutor do consumo na atual dinâmica mercantil, e traz consigo um conjunto de efeitos negativos. A literatura sobre este fenômeno tem se reservado a interpretá-lo a partir de uma abordagem sobre os objetos. Concomitantemente, os atores que sofrem o fenômeno apontado são indivíduos (Martarello, 2020).

Esta pesquisa, fruto de uma dissertação de mestrado ${ }^{1}$ do autor, objetiva apontar a ocorrência do fenômeno de obsolescência programada

\footnotetext{
1 A pesquisa intitulada "A tecnologia com prazo de validade: reflexões acerca da obsolescência programada em serviços públicos" foi defendida em 2018, na Unicamp, sob orientação de Rafael de Brito Dias.
} 
em serviços públicos. No plano metodológico, este estudo se configura como exploratóriointerpretativo, de objetivo básico-aplicado, com abordagem qualitativa. Para o seguimento da proposta da pesquisa, foi apreciado o caso da Máfia das Próteses. Na coleta de dados sobre o caso, foram utilizadas técnicas bibliográficas e documentais. A pesquisa bibliográfica concentrouse em uma obra do diretor da Associação Brasileira de Planos de Saúde. Já a pesquisa documental está pautada nos documentos parlamentares produzidos pela investigação da Assembleia Legislativa do Estado do Rio Grande do Sul e do Congresso Nacional, ambos dentro do âmbito da Máfia das Próteses. Esta última teve, como parte da estratégia de investigação, a participação de acusados e indivíduos que representavam agências de regulação, além de representantes profissionais; associações profissionais; o Ministro da Saúde; um Delegado da Polícia Civil; membros do judiciário; e especialistas e representantes de empresas do setor de OPMEs². Ademais, foi utilizado, como fonte de informação, o material jornalístico do Portal G1 relacionado ao caso durante o período de 4 de janeiro de 2015 a 4 de janeiro de 2018. Para a análise de todos os dados coletados, foi utilizado, como categoria analítica do construto obsolescência programada, o conjunto de descritores do fenômeno listado por Martarello (2020).

\section{Obsolescência programada}

Obsolescência programada é um conjunto de ações empreendidas por parte do produtor com o objetivo de estabelecer o decaimento gradativo de algum atributo de uma mercadoria para estimular artificialmente a demanda pelo consumo. Tratar deste fenômeno é, em si, questionar a linearidade evolutiva da ciência e tecnologia, bem como apontar como os valores políticos e econômicos contaminam e engendram a ciência e o aparato tecnológico.

Após ampla revisão bibliográfica sobre o tema, Martarello (2020) destaca os elementos necessários para que uma prática possa ser caracterizada como obsolescência programada. São eles: a produção intencional, ou não intencional, estabelecendo o término da vida útil; a perversão das propriedades de uso do produto; a generalização adaptativa da prática no setor; a contaminação da tomada de decisão do consumidor para venda enganosa; o enfraquecimento do movimento tradicional de destruição-criativa para um de destruição-retroalimentadora; a inclinação da eficiência técnica à lógica de mercado; o desperdício compulsivo; a perseguição de ganhos monetários por meio da não satisfação de necessidades; a operação em nível molecular das relações capitalísticas; e o comportamento dentro dos tipos de obsolescência programada, podendo ocorrer, simultaneamente, mais de um tipo.

Em seu entendimento, o fenômeno de obsolescência programada pode atuar não só em itens físicos, mas também em serviços ${ }^{3}$. Para isso, Martarello (2018) realizou uma minuciosa reflexão do funcionamento e organização deste setor. Como resultado, a falta de visualização da concretização material dos serviços e/ou falta de entendimento da produção de serviços como uma forma de mercadoria é decorrente de uma visão fetichista da mercadoria. Além disso, é possível que esta categoria de trabalho esteja inserida dentro da valorização do capital e da luta de classes.

Derivam dessas ramificações materiais e imateriais, atualmente, três formas variantes de ocorrência da obsolescência programada: de qualidade; de função; e de desejabilidade. A obsolescência

\footnotetext{
2 Medtronic Comercial Ltda, Johnson \& Johnson do Brasil Industria e Comércio de Produção para a Saúde Ltda, Stryker do Brasil Ltda, Boston Scientific do Brasil Ltda, Intelimed Comércio e Representações Ltda, IOL Implantes Ltda, Gusson Equipamentos Médicos e Hospitalares Ltda, Brumed Implantes, Orcimed Indústria e Comércio Ltda, Síntese Comércio Hospitalar Ltda, Litormed Comércio e Produtos Médicos Ltda, Biocath Comércio e Produtos Hospitalares Ltda e Stehl Comércio e Representação de Produtos Médicos Ltda. 3 São características da atividade de serviço: prática de negócio para além dos limites físicos do estabelecimento; criação de relacionamento social entre prestador e cliente (Antunes, 2011); agregado intangível como resultante do processo (Kotler; Armstrong, 2015); possibilitar a satisfação de necessidades não só físicas como, também, subjetivas; perpétua variabilidade de execução (Antunes, 2011); poder, ou não, estar acompanhado de um bem; ser produzido e consumido simultaneamente e, por isso, ter improvável nível de estoque (Antunes, 2011; Grönroos, 1995).
} 
programada de qualidade é o planejamento para que uma mercadoria, em um tempo não muito longo, quebre ou perca a eficácia em satisfazer a necessidade. A obsolescência programada de função ocorre no momento que o produtor decide retardar a introdução de uma inovação para que em etapas sejam inseridos microaperfeiçoamentos tecnológicos. A obsolescência programada de desejabilidade ocorre quando produtores, após introduzirem mercadorias, buscam posicioná-las na mente do consumidor como obsoletas ou antiquadas, mesmo que estejam aptas para uso e sem nenhum problema de performance ou em suas propriedades.

No próximo item serão descritas características gerais do serviço de saúde no Brasil, de forma a caracterizar o cenário pelo qual, posteriormente, será discutida a ocorrência da prática de obsolescência programada.

\section{O serviço de saúde no Brasil}

Os serviços de saúde objetivam proporcionar não só o alívio ao mal-estar, mas agir preventivamente à salvaguarda das condições físicas e psicológicas humanas. Isso possibilita a continuidade da rotina humana, impedindo distúrbios e gastos sociais. O financiamento destes serviços por parte do Estado visa proteger a população de doenças e agravos, mesmo em situações financeiras desfavoráveis. Há também a saúde suplementar, realizada pelo financiamento particular, com o objetivo de obter uma diferenciação de atendimento e escolha pelo poder aquisitivo.

A prestação de serviços públicos de saúde apresenta uma série de desafios operacionais, tais como: desigualdades regionais na distribuição de serviços, profissionais e recursos (Scheffer et al., 2018); aumento do gasto em saúde em todo o mundo (Silva; Viana; Nunes, 2011); situações excepcionais que sobrecarregam a demanda por serviços e recursos; mudanças demográficas, epidemiológicas e sociais, assim como o aumento do padrão de custos dos serviços; e proximidade comercial de profissionais com fornecedores (Brasil, 2015a).

Ao focar nos médicos, dos mais de $450 \mathrm{mil}$ profissionais, a maioria possui mais de um vínculo de trabalho e atua, ao mesmo tempo, na esfera pública e na privada (Scheffer; Biancarelli; Cassenote, 2011; Scheffer et al., 2018). Ademais, esses profissionais têm alta jornada de trabalho e elevado nível de estresse laboral, além de estarem cotidianamente em contato com riscos biológicos e químicos.

A indústria médica relaciona-se, de forma mutualística, com duas outras indústrias - a indústria farmacêutica e a indústria de OPMEs - de modo que ambas se tornaram substanciais para a prática médica. Se, por um lado, em decorrência da prescrição de medicamentos e uso de OPMEs, a prática médica tornouse mais eficiente, produtiva e demandada, por outro, o médico possibilita para essas indústrias a abertura de mercado para vendas e a confiabilidade sobre o produto.

A indústria de OPMEs, em particular, tem ganhado notoriedade principalmente pela chamada transição epidemiológica de doenças parasitárias e infecciosas rumo às doenças crônicas e degenerativas (Silva; Viana; Nunes, 2011), bem como pelo aumento de doenças cardíacas e da população idosa (Felix, 2007). Além disso, a indústria de OPMEs é um dos setores que mais investe em Pesquisa e Desenvolvimento (Pieroni; Reis; Souza, 2010).

O funcionamento desta indústria no Brasil tem se apoiado na estabilidade e obrigatoriedade do gasto estatal em saúde e, caso o indivíduo possua cobertura de um plano assistencial, as operadoras de saúde são responsáveis pelo pagamento. Como resultado, em 2014, este setor faturou R\$7 bilhões e o custo com OPMEs dos serviços de saúde, no Brasil, foi de R\$ 20 bilhões (Brasil, 2015b).

De forma geral, os procedimentos de OPMEs no Sistema Único de Saúde (SUS) seguem o Sistema de Gerenciamento da Tabela de Procedimentos, Medicamentos e OPME. A aquisição, o recebimento, a utilização e o controle de OPMEs, até 2017, estavam disciplinados pela Portaria no 403, de maio de 2015, do Ministério da Saúde. Postula a referida portaria que, para a aquisição, deve haver planejamento, sendo a aquisição de acordo com a demanda estipulada, considerando as especificações técnicas que se referem a critérios de qualidade. Na unidade hospitalar, a OPME deve ser armazenada e, em seguida, esperar a solicitação do profissional de saúde encarregado do ato cirúrgico. 
Para sua utilização, é obrigatória a existência da Autorização de Internação Hospitalar e/ou de procedimento ambulatorial agendado. Em relação ao controle, a responsabilidade recai sob o cirurgião e sob o diretor técnico das instituições hospitalares. Cabe ao médico que indica e realiza o procedimento realizar registros pormenorizados acerca do consumo de OPMEs, de forma a permitir a identificação, rastreabilidade, histórico médico, inclusive em caso de não utilização ou danificação do material ou de sua embalagem.

$\mathrm{Na}$ saúde suplementar, as operadoras de saúde têm adotado práticas que vão desde o estabelecimento de protocolos de autorização e precificação dos materiais, passando por melhores práticas comerciais com os agentes do mercado, até a análise da indicação de procedimentos e de requisição de materiais (Alencar, 2016).

Contrariando a missão do cuidado em saúde, o anseio e investimento social em saúde, os objetivos intencionados pelas diretrizes e o funcionamento do SUS, será exibida, no item seguinte, uma prática fraudulenta na área da saúde com o objetivo de enriquecimento de agentes particulares.

\section{A Máfia das Próteses}

Com o objetivo de induzir, de maneira artificial, a demanda por serviços e dispositivos médicos, houve um conjunto de empreitadas envolvendo médicos, clínicas, hospitais, gestores, funcionários públicos e empresas de OPMEs. Essas ações se concentraram, em sua maioria, na realização de cirurgias desnecessárias ou de intervenções com o intuito de piorar o bem-estar; em preços superfaturados do procedimento cirúrgico; no uso de produtos além do necessário; em fraudes processuais; cartelização de mercado; em manipulação do Judiciário e de procedimentos licitatórios; e em incorporação pessoal de materiais cirúrgicos (Ramos, 2016; Brasil, 2015a; 2015b; Rio Grande do Sul, 2016) ${ }^{4}$. Além destes apontamentos, ainda houve cirurgias fantasmas; o uso de dispositivos médicos implantáveis com prazo de validade vencido; danos propositais nas próteses com objetivo de forçar sua reposição; e cobranças de dispositivos médicos implantáveis já pagos pela assistência privada (Brasil, 2016).

As irregularidades médico-hospitalares ocorreram tanto no sistema público de assistência médica, como no privado, principalmente em áreas que contam com o uso de OPMEs, como ortopedia, cardiologia, neurologia e odontologia ${ }^{5}$.

\section{Modus Operandi}

O fluxo da cadeia de suprimentos dos dispositivos médicos implantáveis começa nos fabricantes ou importadores, passando para os distribuidores, nos quais a atuação é por monopolização territorial ${ }^{6}$. Em seguida, o SUS ou o Plano Assistencial compra o produto, que é encaminhado ao hospital. Este, por sua vez, cobra uma margem de $30 \%$ pelo armazenamento, higienização e esterilização dos dispositivos médicos implantáveis. Dessa forma, desde o custo do produto até o preço final - passando por tributos, fretes, seguros e comissões aos vendedores e médicos -, há uma diferença de $3.000 \%$.

Depois do desenvolvimento, os materiais não são muito caros - excluindo o retorno sobre investimento em Pesquisa e Desenvolvimento. Além de saírem do fabricante com preços elevados, chegam ao cliente final, ao SUS ou à Assistência Privada, com um preço abusivo e superfaturado. A própria fixação de preços proposta pela tabela do SUS determina valores muito acima do normal, até mesmo em comparação aos

\footnotetext{
4 Houve paciente com perda de controle do esfíncter e sem poder movimentar uma das pernas, prótese implantada em posição invertida, intervenções cirúrgicas desnecessárias, cobrança ao paciente de material utilizado em procedimentos cirúrgicos (Brasil, 2015b).

5 Os crimes apontados no caso brasileiro foram: lesão corporal (Art. 129 do Código de Processo Penal); falsificação de documento particular (Art. 298 do Código de Processo Penal); falsificação de documento público (Art. 299 do Código de Processo Penal); estelionato (Art. 171 do Código de Processo Penal); associação criminosa (Art. 288 do Código de Processo Penal); e falsidade ideológica (Art. 297 do Código de Processo Penal). Contudo, para Anjos, (2019) ainda seria possível a tipificação penal de crimes contra a ordem econômica e de consumo (Art. 4 da Lei 8137/9o); lavagem de dinheiro (Art. 1 da Lei 9.613/98); contra a ordem tributária (Art. 1 e Art. 2 da Lei 8.137/9o); corrupção (Art. 333 e 317 do Código de Processo Penal); e falsificação, corrupção, adulteração ou alteração de produto destinado a fins terapêuticos ou medicinais (Art. 273 do Código de Processo Penal).

6 Mesmo que houvesse um material mais barato em outra região, não seria possível efetuar a compra, o que possibilita a grande variação dos preços.
} 
preços oferecidos em hospitais privados de renome e que são referência em cuidado em saúde.

Os médicos, indutores do processo, capturavam potenciais vítimas, elaboravam laudos distintos encaminhando-os ao Sistema Único de Saúde no qual, artificialmente, o problema do paciente é maximizado -, determinavam todo o material da cirurgia, simulavam procedimentos e criavam estoques paralelos para venderem a outros consumidores. Os profissionais da saúde eram orientados pelas empresas OPMEs acerca de como manipular licitações, inserindo as características específicas de um fornecedor no edital. Graças à Resolução 1.956 do Conselho Federal de Medicina, era possível escolher entre três fornecedores. Os Planos Privados e o SUS não faziam uma intensa análise dos casos, nem mesmo um protocolo a ser verificado, o que contribuiu para as práticas. Os hospitais em que eram realizadas as cirurgias não se responsabilizavam diretamente pela fiscalização e ocorrência dos procedimentos.

Os pagamentos irregulares recebidos pelos médicos estavam sendo feitos por meio de recebimento por prestação de serviço. Por conseguinte, os médicos começaram a se tornar pessoas jurídicas, abrindo empresas inexistentes com o objetivo de confundir a justiça e procederem com o recebimento indevido. Eles também recebiam de outras formas. Além de dinheiro, aceitavam presentes, viagens e congressos. Todos esses atos configuram-se como falta de ética profissional.

Em muitos casos, o pedido para o procedimento cirúrgico era negado, devido à contestação de indicação, ao preço dos materiais e/ou negação da cobertura. Para garantir que o procedimento cirúrgico ocorresse, este sofisticado esquema criminoso contava com escritórios de advocacia especializados em ajuizar procedimentos para a implantação de dispositivos médicos. 0 médico, além de referenciar o escritório ao paciente, documentava a necessidade de urgência para a operação. Nesta etapa, já havia o pedido com materiais com preços abusivos. O tribunal, com as melhores intenções, tutelava a realização da cirurgia em prol do zelo pela vida, pelo direito à saúde e pelo direito do consumidor. De acordo com a Comissão Parlamentar de Inquérito (CPI) da Câmara de Deputados, foi compreendido que, dentre os procedimentos cirúrgicos irregulares, 80\% se deram através de liminares da Justiça. Os valores gastos com judicialização, segundo Ramos (2016), foram de R\$ 7 bilhões para o sistema público; para as operadoras, R\$ 1,2 bilhão.

Abaixo, um diagrama explicativo da Máfia das Próteses:

\section{Figura I - Representação esquemática do funcionamento da Máfia das Próteses}

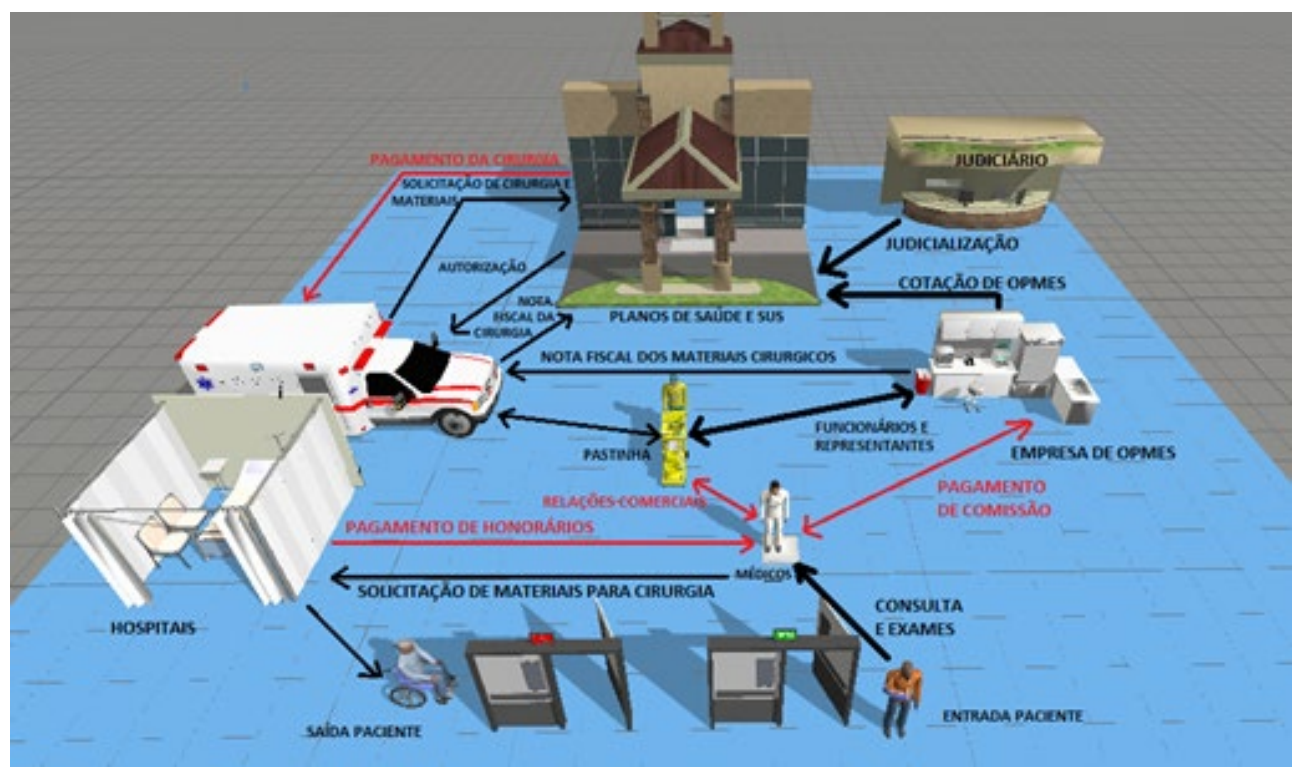

Fonte: elaboração própria a partir do uso do FlexSimHC 5.3 "/figura" 


\section{Casos ilustrativos}

Com a disponibilização dos relatos das vítimas em sessão pública, foi possível ter contato com as ações praticadas. Todos os casos apresentados abaixo foram relatados na CPI realizada pela Assembleia Legislativa do Rio Grande do Sul.

\section{Caso 1}

Em S. M. V., foram realizadas seis cirurgias. A primeira, no valor de R\$ $48 \mathrm{mil}$, em que foram colocados quatro parafusos, espaçadores e cages. Todos pertencentes à Intelimed. Após a cirurgia, suas dores aumentaram. Ela foi submetida a um segundo procedimento, com a finalidade de realizar um enxerto ósseo, com material também fornecido pela Intelimed. Um ano depois, foi realizada a terceira cirurgia, na qual o médico não só acrescentou mais dois parafusos, mas também substituiu os quatro instalados durante o primeiro ato cirúrgico por outros quatro da mesma marca. Mesmo após a cirurgia, o médico continuou realizando infiltrações em sua coluna e em sua espinha dorsal, com o objetivo de tentar bloquear a dor. Sem sucesso, a paciente foi submetida ao quarto procedimento cirúrgico, no qual foram retirados todos os parafusos instalados. Todavia, um dos parafusos quebrou e se alojou no sacro, o que acarretou novos problemas. Já idosa, ela foi submetida a uma quinta cirurgia, com um novo médico. Embora a cirurgia tenha custado mais de R\$ 100 mil, contando com a instalação de dez parafusos importados, o ato não resolveu o problema e ainda trouxe mais dores.

Exames posteriores avaliaram que um dos parafusos estava pressionando nervos da coluna. Na sexta cirurgia, com um novo médico, este se prontificou a retirar somente os parafusos que estavam nos nervos, dizendo que nada mais poderia ser feito. Além de ter duas das cirurgias feitas por judicialização, a vítima relatou que apareceram novos problemas, como hérnia e afrouxamento posicional de espaçadores. Após a apresentação de aquecimento em exames, a suspeita de que o dispositivo médico implantável era falsificado foi especulada, e posteriormente comprovada por análise oficial do Laboratório de Metalurgia Física da Universidade Federal do Rio Grande do Sul.

\section{Caso 2}

Em E. F., segundo alguns médicos, não foi identificada a necessidade de cirurgia. Contudo, com a persistência das dores, ele procurou o médico F. S., que mencionou a necessidade imediata de cirurgia. Foram implantados uma placa e oito parafusos em sua cervical. Após a cirurgia, com o aparecimento de problemas de deglutição, E. F. procurou médicos de outras especialidades e foi, até mesmo, submetido a uma endoscopia, que não apontou nada. Outro exame realizado posteriormente mostrou a necessidade de uma nova cirurgia para firmar os parafusos fixados em sua cervical, pois eles estavam frouxos. Este segundo ato cirúrgico foi acompanhado por outro médico, que também realizava procedimentos no paciente. Tal médico relatou espanto pela forma de manejo com a qual F.S. atuou sobre a cervical do paciente. Após a cirurgia, novamente houve complicações, resultando em uma infecção e, posteriormente, um médico descobriu que o esôfago do paciente estava furado. Novos exames apontaram dificuldade funcional na passagem do alimento entre a boca e o estômago; evaginação; invólucro com cavidade entre a faringe e o esôfago; e dois parafusos no esôfago, que estava com infecção ${ }^{7}$. Para a recuperação do paciente, foram retirados os parafusos e as placas implantadas.

\section{Caso 3}

A. S. C., com protrusões discais difusas nas vértebras L2-L3, L3, L4, L4-L5 e L5-S1, foi submetido a uma cirurgia, tratamento não conservador para esta enfermidade. Ao final do procedimento, foi constatado o fato de que apenas quatro pinos foram colocados, nenhum atuando sobre a L4. Desse modo, foi agendada uma segunda cirurgia. Nela, foram retirados os materiais da cirurgia antiga e instalados seis novos parafusos. A justificativa aceita pelo paciente foi a de que os novos parafusos eram

\footnotetext{
7 No exame, foi constatado que o paciente tinha "disfagia orofaríngica com penetração laríngea, divertículo ou pseudodivertículo secundário afistula na transição faringo-esofágica” (Rio Grande do Sul, 2016, p. 187).
} 
importados e, logo, de melhor qualidade. Contudo, as dores continuaram. Segundo a equipe de operação, era algo psicológico. Isso foi desmentido por novas avaliações, que apontaram, por meio de exames, que o dispositivo implantado estava pressionando os nervos, além de estar com defeito no formato. Diante disso, foi realizada a terceira cirurgia, que retirou e colocou o mesmo dispositivo médico implantável, o que não resolveu o problema. No quarto ato cirúrgico, o sucesso também não foi alcançado. Por fim, o paciente foi submetido à instalação de um neuroestimulador.

\section{Discussão da obsolescência programada em serviços públicos}

No primeiro caso, é possível observar os diferentes problemas nas propriedades do material, que o levaram à ruptura e deficiência operativa. Também são encontrados, neste caso, problemas na operação do serviço médico, que intencionalmente buscava criar necessidades para contínuas intervenções futuras. Esta última constatação também aparece no segundo caso. Dessa maneira, compreende-se que o problema de desempenho está totalmente ligado aos procedimentos cirúrgicos executados e não somente ao material.

No último caso, é possível averiguar a ocorrência de problemas com a propriedade do material, que ficou torto e, por conta disso, necessitaria de um novo equipamento e um novo procedimento cirúrgico para realizar a troca. Em contrapartida, sobre o serviço executado pelo médico, encontramse diversas deficiências: desde não executar a solução sob toda a necessidade do consumidor de serviços médicos, até causar uma nova moléstia e erro proposital no procedimento. Ademais, é visto um fator de desejabilidade, pelo qual se justificou a troca por um artigo com qualidade supostamente superior por ser importado.

Nos casos estudados, e em sintonia com os descritores do fenômeno de Martarello (2020), foram encontradas intervenções cirúrgicas que estabeleceram, intencionalmente, o término da vida útil do procedimento médico, o que ocorreu em várias especialidades e localidades do país. Os médicos operaram perseguindo os ganhos monetários, submetendo a técnica à lógica de mercado por meio da não satisfação do serviço prestado. Para a ocorrência dos atos cirúrgicos, houve não só a manipulação de consumidores e das partes envolvidas - SUS, planos privados, Judiciário - para a ocorrência das cirurgias, mas também práticas em âmbito molecular de relações de mercado. Durante os procedimentos, foi possível observar desperdício compulsivo para maximizar lucros do procedimento atual e futuros, de modo a gerar um novo procedimento devido ao erro ou ao novo problema criado. Foi possível, ainda, encontrar casos de dois tipos de obsolescência programada.

Atua, aqui, a mesma téchne, o fenômeno de obsolescência programada, mas sendo realizado por prestadores de serviço por meio do procedimento executado, afastado - salvo em alguns casos de qualquer material técnico com decaimento de vitalidade. Com isso, temos uma forma de obsolescência programada por meio de serviços.

No Quadro 1, é apresentada uma síntese das ações que inferem a existência de alguma forma de obsolescência programada, de acordo com cada caso exposto, assim como o tipo que se representa.

\section{Quadro I - Tipos de obsolescência programada na Máfia das Próteses}

\begin{tabular}{|l|l|l|}
\hline Casos & Ações & Tipo de obsolescência programada \\
\hline \multirow{2}{*}{1} & $\begin{array}{l}\text { Procedimentos repetitivos, irresolutos e fracassados; } \\
\text { Realização de trocas estéreis e inapropriadas; } \\
\text { Procedimento incorreto; }\end{array}$ & Obsolescência programada de qualidade em serviços; \\
& $\begin{array}{l}\text { Surgimento de novos procedimentos; } \\
\text { Material rompido; } \\
\end{array}$ & Obsolescência programada de qualidade. \\
\hline
\end{tabular}




\begin{tabular}{|c|c|c|}
\hline Casos & Ações & Tipo de obsolescência programada \\
\hline 2 & $\begin{array}{l}\text { Ausência de necessidade de realização de serviço; } \\
\text { Surgimento de novos procedimentos; } \\
\text { Procedimento incorreto; } \\
\text { Procedimentos repetitivos, irresolutos e fracassados. }\end{array}$ & Obsolescência programada de qualidade em serviços \\
\hline 3 & $\begin{array}{l}\text { Procedimentos repetitivos, irresolutos e fracassados; } \\
\text { Procedimento incorreto; } \\
\text { Realização de trocas estéreis e inapropriadas; } \\
\text { Surgimento de novos procedimentos; } \\
\text { Substituição de produto/serviço por questões de status; } \\
\text { Material desprovido ou minorado de suas propriedades. }\end{array}$ & $\begin{array}{l}\text { Obsolescência programada de qualidade em serviços } \\
\text { Obsolescência programada de desejabilidade em serviços } \\
\text { Obsolescência programada de qualidade }\end{array}$ \\
\hline
\end{tabular}

São indicativos deste tipo de obsolescência programada no serviço médico: a ocorrência da recidiva - isto é, a manutenção do paciente no mesmo estado de enfermidade, ou a aquisição de um novo ataque de enfermidade após a intervenção médica ${ }^{8}$; a metalose, um tipo de reação intracorporal associada ao desgaste de uma prótese de má qualidade ou que sofreu uma micromovimentação; a ocorrência de quebra, corrosão, fadiga, deterioração e, até mesmo, a danificação proposital; o erro de assistência ${ }^{9}$; a indicação de procedimentos desnecessários ou inoportunos e, mesmo com a necessidade, com emprego de dispositivos além do essencial e/ou simulação de procedimentos cirúrgicos.

Em decorrência desta empreitada pela maximização da remuneração e dos benefícios pessoais o poder de compra do Estado via compras governamentais foi deturpado, houve perda de recursos em cirurgias desnecessárias, lesão à saúde pública e foram criados custos de agência ${ }^{10}$. 0 superfaturamento e as cirurgias desnecessárias não só contribuíram para a elevada mensalidade dos planos de saúde, como tornaram infrutífera parte da renúncia fiscal empreendida pelo Estado em gastos com saúde privada. Em 2012, por exemplo, o gasto tributário foi de R\$ 24,4 bilhões, isto é, igual a aproximadamente $23 \%$ do orçamento do SUS. Essa constatação reforça que a renúncia fiscal é um mecanismo que prejudica a universalização, ou seja, um obstáculo para o financiamento do Sistema Único de Saúde ${ }^{11}$.

Sobre os aspectos intrínsecos à profissão médica, verifica-se um conjunto de ações contra a saúde pública e contra a missão da medicina ao atentar contra o zelo pelo prestígio da profissão, não respeitar o paciente e usar de seus conhecimentos para causar sofrimento. Além disso, há atividades que são graves infrações ao Código de Ética Médica, uma vez que ao profissional é vedado: causar dano ao paciente (Art. 1); indicar atos desnecessários (Art. 14); utilizar da profissão para cometer ou favorecer crimes (Art. 30); elevar a gravidade da avaliação clínica, complicar o tratamento e exceder-se no número de procedimentos ao paciente (Art. 35); exercer de forma mercantil a medicina (Art. 58); aceitar remuneração por procedimento não realizado (Art. 59); realizar dupla cobrança pelo ato não executado (Art. 66); praticar medicina em associação com empresas fabricantes de itens para o trabalho médico e/ou obter vantagem desta relação (Art. 68 e 69) (CFM, 2010).

8 Não se trata, aqui, de um evento adverso.

9 Toda ação planejada de assistência pelo desvio do processo de cuidado, estabelecimento de um plano terapêutico errado, ou pela não conclusão de um procedimento executado, visando algum objetivo monetário (Reason, 200o; Reason, 2001 apud Couto et al., 2017).

10 Despesas de monitoramento, com seguros, e perdas residuais. Em alguns procedimentos, são utilizados os "fiscais de cirurgia", que são médicos contratados pelos planos de saúde para assegurar que o procedimento é realizado corretamente.

11 Pontua-se, aqui, a inconsistência lógica do mecanismo, uma vez que não há limite para o gasto, o que está relacionado com a obtenção de um serviço concentrado e de mercado. 


\section{Considerações finais}

Ao estudar o fenômeno de obsolescência programada, Martarello (2018) delineou a possibilidade da ocorrência do fenômeno sobre serviços públicos. Desse modo, foi exibido um ator e um meio de ocorrência que a literatura sobre obsolescência programada ignorava, embora possua elevada importância econômica e seja provedor de serviços a toda uma nação.

A descrição do funcionamento da indústria de saúde no Brasil e o estudo dos casos da mercantilização de enfermidades, por meio da Máfia das Próteses, proporcionou a ilustração da atuação do fenômeno de obsolescência programada na área de serviços públicos de saúde. No caso dos serviços médicos, podem aparecer as seguintes características: procedimentos repetitivos, irresolutos e fracassados; realização de trocas estéreis e inapropriadas; procedimentos incorretos; surgimento de novos procedimentos e ausência de necessidade de realização de serviço.

Pode-se, assim, afirmar que as ações de obsolescência programada têm afetado a população brasileira nos mais diferentes âmbitos e trazido efeitos prejudiciais aos cofres públicos e aos serviços oferecidos pelo Estado. Alerta-se ainda que, embora as ações aqui descritas se concretizem por meio da formação de uma organização criminosa, os médicos podem estar atuando a obsolescência programada de forma isolada.

Por fim, a partir do caso analisado, é possível não só a contribuição para um novo horizonte de eventos para os pesquisadores da obsolescência programada, mas também para campos de estudos que problematizam a relação entre ciência, tecnologia e sociedade e/ou sociedade e consumo.

\section{Referências}

ALENCAR, A. C. F. Aquisição e utilização das órteses, próteses e materiais especiais - OPME e os facilitadores do superfaturamento no sistema de saúde. 2016. 34 f. Monografia (Graduação em Gestão em Saúde Coletiva). Universidade de Brasília, Brasília, 2016. Disponível em: < https://bdm.unb.br/ handle/10483/13620>. Acesso em: 15 set. 2021.
ANJOS, J. F. Práticas fraudulentas na área da saúde: um crime contra a vida humana e financeira das instituições. 2019. Monografia (Graduação em Ciências Jurídicas) Universidade de Taubaté, Taubaté, 2019. Disponível em: < http://repositorio.unitau.br/jspui/ handle/20.500.11874/3591>. Acesso em: 15 set. 2021.

ANTUNES, D. J. N. Capitalismo e desigualdade. 2011. 258 f. Tese (Doutorado em Ciências Econômicas) - Universidade Estadual de Campinas, Campinas, 2011. Disponível em: <http://repositorio.unicamp.br/jspui/handle/ REPOSIP/286378>. Acesso em: 15 set. 2021.

BRASIL. Congresso Nacional. Câmara dos Deputados. Comissão Parlamentar de Inquérito destinada a investigar a Máfia das Órtesese Próteses no Brasil. Reunião n.o6o8/15. Brasília, DF, 2015a. Disponível em: <https://www.camara. leg.br/internet/SitaqWeb/TextoHTML. asp?etapa $=11 \&$ nmComissao $=\mathrm{CPI} \% 20-\% 20$ M\%C3\%Arfia\%2odas\%20\%C3\%93rteses\%20 e\%2oPr\%C3\%B3teses\%2ono\%20 Brasil\&tpReuniaoEvento=AP\%20c/\%2O Convidado\&dtReuniao=19/05/2015\&hrInicio=14:14: oo\&hrFim=17:10:oo\&origemDiscurso $=\& n m L o c a l=P$ len\%C3\%Arrio\%2oPrincipal\%20-\%2oCD\&nuSessao $=0608 / 15 \&$ nuQuarto=o\&nuOrador $=0 \&$ nuInsercao $=0$ \&dtHorarioQuarto=14:14\&sgFaseSessao $=\&$ Data $=19 /$ 05/2015\&txApelido=\&txFaseSessao=\&txTipoSessao =Parlamentar\%2ode\%2oInqu\%C3\%Agrito\&dtHora Quarto=14:14\&txEtapa=>. Acesso em: 24 jan. 2020.

BRASIL. Congresso Nacional. Câmara dos Deputados. Comissão Parlamentar de Inquérito destinada a investigar a Máfia das Órteses e Próteses no Brasil. Relatório Final. Brasília, DF: 2015b. Disponível em: <https://www.camara.leg. br/proposicoesWeb/prop_mostrarintegra?codte or $=1362241 \&$ filename $=R E L+2 / 2015+$ CPIORTES $>$. Acesso em: 20 jan. 20.

BRASIL. Portaria interministerial $n^{0} 403$, de 07 de agosto de 2015. Disciplina a aquisição, o recebimento, a utilização e o controle de Órteses, Próteses e Materiais Especiais (OPME) pelas Unidades Hospitalares subordinadas à Secretaria de Atenção à Saúde do Ministério da Saúde (SAS/MS). Diário Oficial da União. Brasília, DF: 2 ago. 2017. Disponível em: <http://bvsms.saude.gov.br/bvs/ 
saudelegis/sas/2015/prto403_06_05_2015.html>. Acesso em: 15 set. 2021.

BRASIL. Congresso Nacional. Senado Federal. Comissão Parlamentar de Inquérito das próteses. Relatório Final. Brasília, DF, 16 ago. 2016. Disponível em: <https://legis.senado.leg.br/sdleggetter/documento?dm=4001079\&ts=15430150407 28\&disposition=inline >. Acesso em: 15 set. 2021.

CFM - CONSELHO FEDERAL DE MEDICINA. Código de ética médica. Brasília, DF: 2010. Disponível em: <http://www.rcem.cfm.org.br/ index.php/cem-atual>. Acesso em: 15 set. 2021.

COUTO, R. C. et al. II Anuário da segurança assistencial hospitalar no Brasil. São Paulo: Instituto de Estudos da Saúde Suplementar, 2017.

DISTRITO FEDERAL. Tribunal de Contas do Distrito Federal. Relatório Final de Auditoria de Regularidade $n^{\circ} 3 \cdot 848 / 15$. Aquisição, armazenamento e dispensação de órteses, próteses e materiais especiais pela Secretaria de Estado de Saúde do Distrito Federal. Brasília, DF: Secretaria de Auditoria, 2015. Disponível em: <https://www.tc.df.gov.br/wp-content/ uploads/2017/o8/OrtesesProteses.pdf >.

Acesso em: 15 set. 2021.

FELIX, J. S. Economia da longevidade: uma revisão da bibliografia brasileira sobre o envelhecimento populacional. In: Encontro Nacional da Associação Brasileira de Economia da Saúde, 8., 2007, São Paulo. Anais [...]. São Paulo: Abres, 2007.

GRÖNROOS, C. Marketing: gerenciamento e serviços: a competição por serviços na hora da verdade. Rio de Janeiro: Campus, 1995.

KOTLER, P.; ARMSTRONG, G. Princípios de marketing. São Paulo: Pearson/Prentice Hall, 2015.

MARTARELLO, R. A. A tecnologia com prazo de validade: reflexões acerca da obsolescência programada em serviços públicos. 2018.

Dissertação (Mestrado Interdisciplinar em Ciências Humanas e Sociais Aplicadas) - Universidade Estadual de Campinas, Limeira, 2018.

MARTARELLO, R. A.. Avançando sobre os entendimentos acerca do fenômeno de obsolescência programada. Revista Tecnologia e Sociedade, Curitiba, v. 16, n. 45, p. 21-35, 2020. DOI: $10.3895 /$ rts.v16n45.11482

PIERONI, J. P., REIS, C., SOUZA, J. O. B. A indústria de equipamentos e materiais médicos, hospitalares e odontológicos: uma proposta de atuação do BNDES. BNDES setorial, Rio de Janeiro, n. 31, 185-226, mar. 2010. Disponível em: <https://web.bndes.gov.br/bib/jspui/ handle/1408/1761>. Acesso em: 15 set. 2021.

RAMOS, P. A. Máfia das Próteses: uma ameaça à saúde. São Paulo: Évora, 2016.

REASON, J. T. Human error: models and management. BMJ, [S.l.], v. 320, n. 7237, p. 768 770, 200o. DOI: 10.1136/bmj.320.7237.768

REASON, J. T. Understanding adverse events: the human factor. In: VINCENT, C.; WILLIAMS, J. Clinical risk management: enhancing patient safety. Londres: BMJ Books, 2001. p. 9-30.

RIO GRANDE DO SUL. Assembleia Legislativa do Estado do Rio Grande do Sul. Comissão Parlamentar de Inquérito das próteses e dos medicamentos. Relatório Final. Porto Alegre: Assembleia Legislativa do Estado do Rio Grande do Sul, 2016.

SCHEFFER, M.; BIANCARELLI, A.; CASSENOTE, A. J. F. Demografia Médica no Brasil: dados gerais e descrições de desigualdades. 1. ed. São Paulo: Conselho Federal de Medicina, 2011.

SCHEFFER, M. et al. Demografia Médica no Brasil 2018. São Paulo: FMUSP, CFM, Cremesp, 2018.

SILVA, H. P.; VIANA, A. L. D.; NUNES, A. A.

Complexo produtivo da saúde, desenvolvimento e incorporação de tecnologias. In: IBÃNEZ, N.; ELIAS, P. E. M.; SEIXAS, P. H. A. (Org.). Política e gestão pública em saúde. São Paulo: Hucitec Cealag, 2011. p. 75-101.

\section{Contribuições dos autores}

Martarello é responsável por todas as etapas da pesquisa e pela redação do manuscrito.

Recebido: 30/07/2021

Reapresentado: 30/07/2021

Aprovado: 14/09/2021 